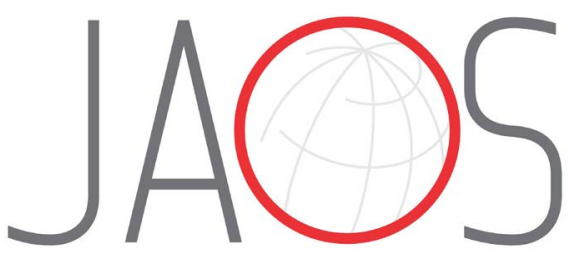
JOURNAL OF APPLIED ORAL SCIENCE

\title{
Assessment of a conservative approach for restoration of extensively destroyed posterior teeth
}

\section{Abstract}

José MONDELLI ${ }^{3}$ iD

Fabio Antonio Piola RIZZANTE ${ }^{2}$

Fabiano Bassalobre VALERA $^{1}$

Renato ROPERTO 2

Rafael Francisco Lia MONDELLI ${ }^{3}$ Adilson Yoshio FURUSE ${ }^{3}$
Submitted: October 17, 2018 Modification: December 17, 2018

Accepted: January 14, 2018

Corresponding address: Fabio Antonio Piola Rizzante Department of Comprehensive Care, Case Western Reserve University, School of Dental Medicine - 2124 Cornell Rd, 44106 - Cleveland - OH - USA Phone: +17344892834 e-mail: fap17@case.edu
Extensive restorations in posterior teeth always bring doubts to the clinicians regarding the best protocol, mainly when structures of reinforcement were lost. Objective: This study aimed to evaluate the effect of beveling on the fracture resistance and pattern of class II (MOD) restored teeth. Methodology: Ninety human premolars were randomly assigned into 9 groups: CTR (control/sound); NC (cavity preparation, non-restored); RU (restored, unbeveled); RTB (restored, entire angle beveling); RPB (restored, partial/occlusal beveling); EC (endodontic access/EA, non-restored); EU (EA, unbeveled); ETB (EA, entire angle beveling); EPB (EA, partial/occlusal beveling). Teeth were restored with Esthet $X$ resin composite and stored in distilled water for $24 \mathrm{~h}$ before the inclusion in PVC cylinders. The axial loading tests were performed with $500 \mathrm{kgF}$ at $0.5 \mathrm{~mm} / \mathrm{min}$ crosshead speed until fracture of the specimens. Fracture resistance and pattern were accessed and data were analyzed using one-way ANOVA and Tukey's HSD test $(\alpha=0.05)$. Results: Mean ( $( \pm S D)$ failure loads ranged from 136.56 (11.62) to 174.04 (43.5) kgF in the groups tested without endodontic access. For endodontically accessed teeth, fracture resistance ranged from 95.54 (13.05) to 126.51 (19.88) kgF. Beveling of the cavosurface angle promoted the highest fracture resistance values $(p<0.05)$ and prevented catastrophic fractures. Conclusions: Cavosurface angle beveling is capable of improving fracture resistance and pattern for both endodonticaly accessed and nonaccessed teeth.

Keywords: Composite resins. Dental cavity preparation. Endodontically treated teeth. Permanent dental restorations.

${ }^{1}$ Private practice, Marília, São Paulo, Brasil.

${ }^{2}$ Case Western Reserve University, School of Dental Medicine, Cleveland, Ohio, United States of America.

3Universidade de São Paulo, Faculdade de Odontologia de Bauru, Departamento de Dentística, Endodontia e Materiais Odontológicos, Bauru, São Paulo, Brasil. 


\section{Introduction}

Restoration of extensively destroyed tooth aims to reestablish function and aesthetics. Extensive cavities are directly associated with lower fracture resistance ${ }^{1-3}$ and are often associated with marginal failures, cracks and total/partial cusp fracture. ${ }^{4}$ This seems to be true for posterior teeth, especially for upper premolars, in which coronary anatomy tends to deflection and separation of the cusps during mastication. ${ }^{2,5-7}$ The depth of the cavity and the involvement of reinforcement structures such as marginal crests and pulp chamber roof (endodontic access) further increase tooth structure deflection as well as stress concentration at the buccal pulpal and lingual pulpal angles. $3,4,8-10$

Despite the large indications for cusp coverage (i.e. crown, onlay, etc) in restorations of extensively compromised teeth, ${ }^{8,11}$ resin composite restorations are cheaper and have adequate physical and mechanical properties such as adhesiveness, elasticity, resilience, and resistance to tensile, shear and compression stresses, thus allowing greater synergy between tooth and restorative material, capable of absorption of masticatory forces ${ }^{2-6,12}$ and reduction in cusp deflection through cusp "splinting". 4-7,13,14 Moreover, the adhesive concepts allow more conservative cavity designs, improving the resistance of tooth reminiscent. ${ }^{1-3}$

Bonding in enamel presents long-term stability. However, enamel is composed of prisms that are often perpendicular to the enamel-dentin junction and can be fractured if the forces are not parallel to this direction. ${ }^{15,16}$ Micro-cracks and consequent degradation of enamel can be prevented by beveling the cavosurface angle and using adequate polymerization and polishing techniques etc. Beveling provides a smoother and more regular enamel surface through the removal of weakened prisms, which could fracture due to polymerization stress of composites, as well as increase the surface area to bonding, contributing to a more stable restoration. ${ }^{15-22}$ Even with all these advantages reported and proved, some clinicians often relegated and even contraindicate beveling claiming it does not promote better restoration performance and/or promotes a lower thickness of the restorative material, over extension of cavity margins and exposure of the restorative material/tooth interface at areas of occlusal contact. ${ }^{23-25}$

This article aimed to evaluate the effect of bevel on the fracture resistance and pattern in MOD class II cavity preparations, with and without endodontic access, after restoration with direct composite. The null hypothesis tested was that there should be no difference between the different cavosurface angle treatments considering the resistance and fracture pattern of direct composite restored teeth, with or without endodontic access.

\section{Methodology}

This investigation had dental preparation (in nine levels) as study factor: positive control (without preparation), two negative control groups (preparations with and without endodontic access and without restoration), and six groups according to enamel beveling and presence of endodontic access (no-enamel bevel, occlusal enamel bevel or entire cavosurface angle beveling, with and without endodontic access). The response variables were fracture resistance (evaluated using a universal testing machine) and fracture pattern (evaluated on a stereomicroscope).

After approval of the local Research Ethics Committee, ninety sound human maxillary premolars with similar dimensions and without any cracks or malformations, extracted due to orthodontic or periodontal reasons, were selected and randomly assigned to 9 different groups $(n=10)$ (Figure 1$)$.

Standardized cavity preparations were performed by a single operator using high-speed handpiece, under water cooling and with brand-new burs (up to 4 preparations before recycling). All cavity measures were double-checked with periodontal probe and digital caliper. Cavities were made auto retentive by using 245 carbide burs (KG Sorensen, Cotia, SP, Brazil).

Cavity characteristics:

- Pulpal wall: flat and perpendicular to longitudinal axis of the tooth with $2 \mathrm{~mm}$ in depth and $1 / 3$ of isthmus aperture;

- Buccal and lingual/palatal walls: flat and convergent to occlusal with $2 \mathrm{~mm}$ in depth;

- Gingival wall: flat and parallel to the pulpal wall with $1.5 \mathrm{~mm}$ thickness and $1 / 3$ of isthmus aperture. All cervical margins were determined in the enamel.

- Axial walls: Flat, convergent to occlusal with 1.5 $\mathrm{mm}$ in depth. 


\begin{tabular}{|l|l|}
\hline CTR & Sound teeth (control group). \\
\hline NC & Teeth with cavity preparation and without restorations (negative control 1). \\
\hline RU & Teeth restored with composite resin and unbeveled cavosurface angle. \\
\hline RTB & Teeth restored with composite resin and beveled cavosurface angle. \\
\hline RPB & Teeth restored with composite resin and beveling of the occlusal portion of the cavosurface angle. \\
\hline EC & Teeth with cavity preparation, pulpal chamber roof removal (endodontic access) and without restorations (negative control 2). \\
\hline EU & Endodontically accessed and restored with composite resin and unbeveled cavosurface angle. \\
\hline ETB & Endodontically accessed and restored with composite resin and beveled cavosurface angle. \\
\hline EPB & Endodontically accessed and restored with composite resin and beveling of the occlusal portion of the cavosurface angle. \\
\hline
\end{tabular}

Figure 1-Group division according to the different treatments

Considering the groups with endodontic access, in addition to the previous characteristics, the pulpal chamber roof was removed (with $\mathrm{n} .4$ round bur KG Sorensen), to simulate an endodontic access. Consequently, there were no axial walls.

For the groups RTB, RPB, ETB, and EPB, a concave bevel was made with a flame-shaped diamond bur (\#1111, KG Sorensen) in slow speed and with approximately $0.5 \mathrm{~mm}$ in length. The length of the bevel was checked with a digital caliper.

After cavity preparation, prophylaxis with pumice was performed on the specimens followed by restoration with a direct adhesive restoration system (Esthet X - Dentsply, York, PA, USA).

For teeth with endodontic access, the pulp chamber was filled using a resin-modified glass ionomer cement (Vitremer, 3M ESPE, Saint Paul, MN, USA), following the manufacturer's recommendations: primer application for $30 \mathrm{~s}$, solvent evaporation with air and light curing for $20 \mathrm{~s}$ using a $540 \mathrm{~mW} / \mathrm{cm}^{2}$ light unit (XL 3000, 3M ESPE, Saint Paul, MN, USA); followed by manipulation of Vitremer 1 powder: 1 liquid, insertion in the pulp chamber using a syringe system (until the material was flat with the proximal boxes of the class II cavity), and light curing for $40 \mathrm{~s}$.

All enamel and dentin walls (including the bevel) were etched with a $35 \%$ phosphoric acid gel (Dentsply) - $30 \mathrm{~s}$ for enamel and $15 \mathrm{~s}$ for dentin. Specimens were washed for $30 \mathrm{~s}$ and dried with absorbing paper followed by application of 2 layers of bonding agent (Prime\&Bond NT - Dentsply). A $5 \mathrm{~s}$ gentle air blast was applied to evaporate the adhesive solvent followed by $10 \mathrm{~s}$ light curing.

The restorative materials were inserted following the oblique incremental technique intercalated with 40 s light curing, starting with the proximal boxes. After restoration, $40 \mathrm{~s}$ additional light curing was performed for each surface (mesial, distal and occlusal). Gross excess materials were removed with \#12 scalpel blade.
Samples were stored in distilled water at ambient temperature $\left(23 \pm 2^{\circ} \mathrm{C}\right)$ for $24 \mathrm{~h}$. Restoration finishing and polishing was performed with \# 3118/1190 F and FF diamond burs (KG Sorensen) and yellow/white Viking silicon abrasive tips (KG Sorensen) associated with resin composite lubricating gel. Then, teeth were included in $20 \mathrm{~mm}$ diameter and $30 \mathrm{~mm}$ height self-curing polystyrene resin $(100 \mathrm{~mL}$ resin: $2 \mathrm{~mL}$ catalyst) using PVC cylinders until $2 \mathrm{~mm}$ below the cementoenamel junction, simulating the position of the alveolar bone crest. A metallic bar was used to ensure the positioning of the cusps parallel to the acrylic base, and the specimens were stored for 7 day in distilled water at ambient temperature.

Axial loading tests were performed using a universal testing machine (EMIC DL 2000, EMIC, São José dos Pinhais, PR, Brazil), with $500 \mathrm{KgF}$ loading cell and $0.5 \mathrm{~mm} / \mathrm{min}$ crosshead speed, until fracture of the specimens. The compression test was performed with an $8 \mathrm{~mm}$ diameter steel cylinder, adapted in a metallic bar with $13 \mathrm{~cm}$ in length perpendicular to the intercuspal axis. Internal portion of cusps were prepared with $8 \mathrm{~mm}$ cylindrical aluminum oxide burs to ensure maximum adaptation with the steel cylinder and to prevent it from sliding and/or incorrect force direction. For each specimen, the result of fracture resistance and fracture pattern were recorded after the axial compression test.

Considering the fracture pattern, the specimens were classified in 2 groups: oblique (1) and longitudinal (2). The results were analyzed by Shapiro-Wilk normality test, one-way ANOVA and Tukey Kramer tests, all with $p<0.05$. In addition, a descriptive analysis was used to calculate the relative percentage of the fracture patterns observed for each group. Figures 2 and 3 show drawings of the fracture patterns observed. 


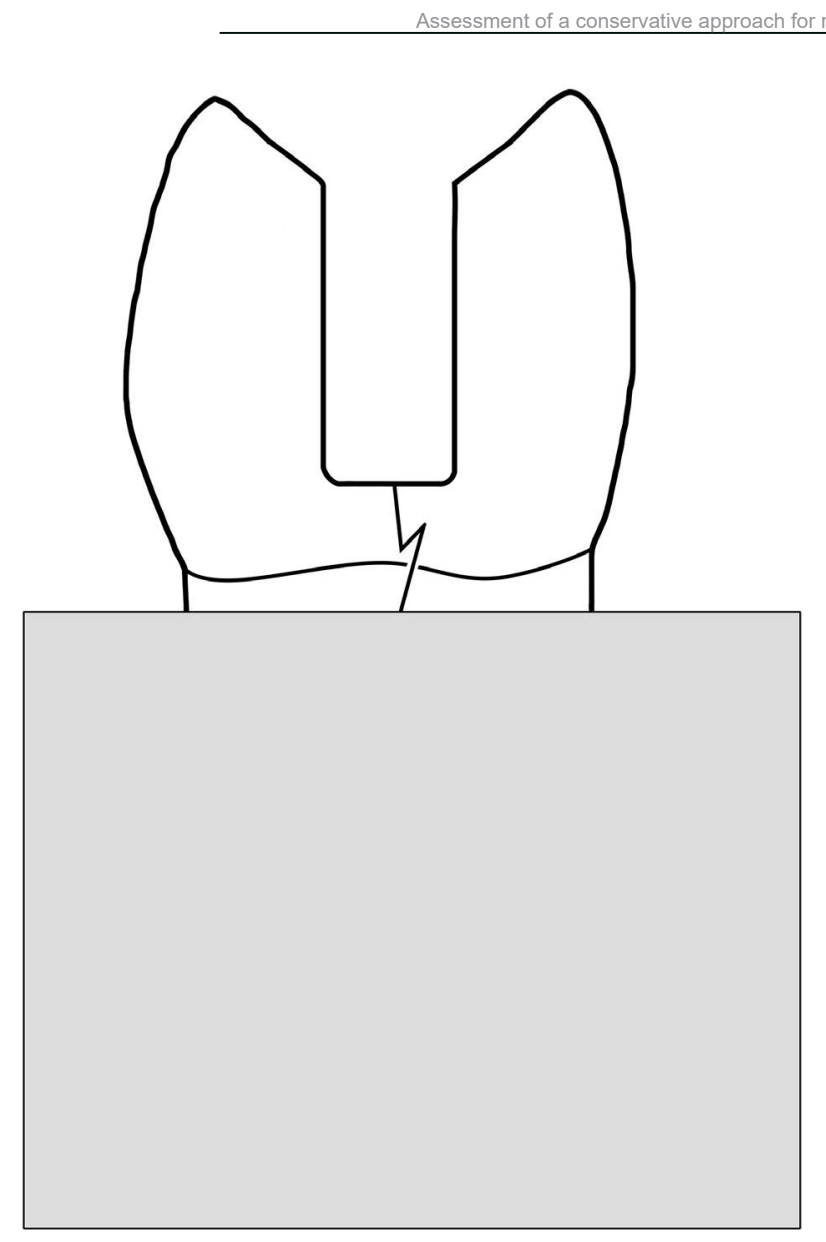

Figure 2- Schematic drawing representing a longitudinal fracture

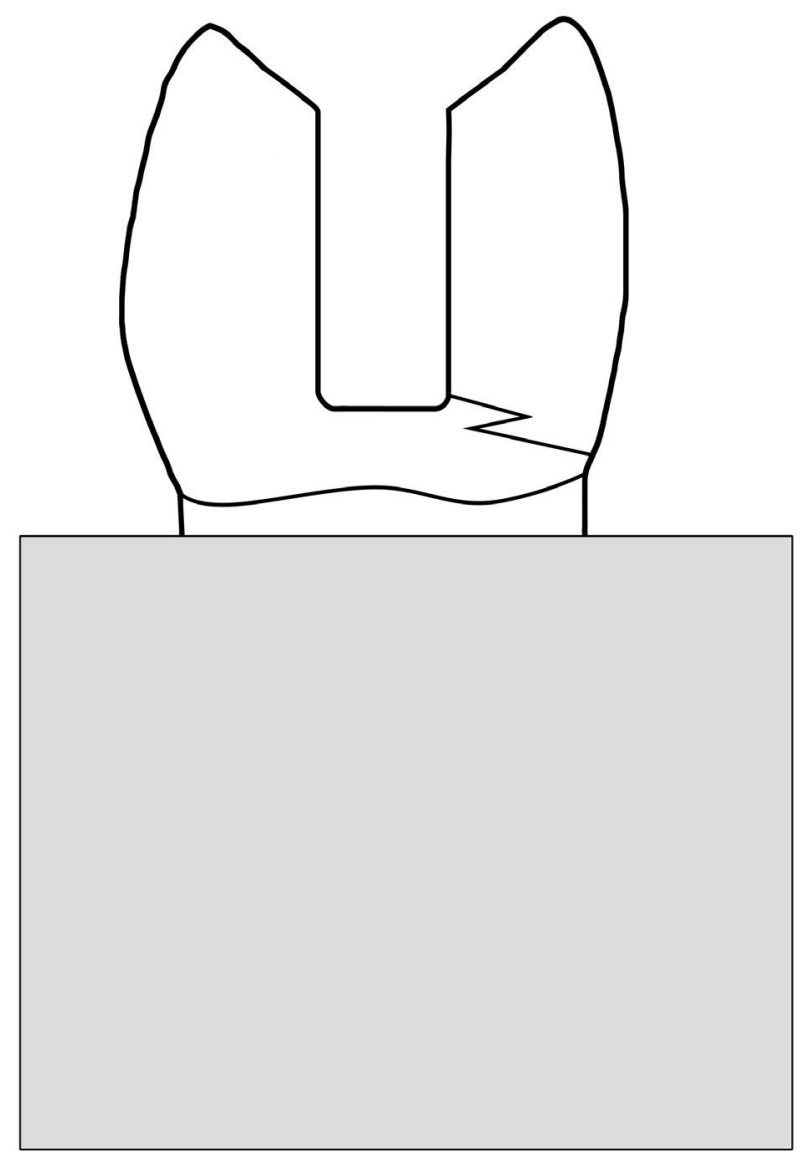

Figure 3- Schematic drawing representing an oblique fracture

Table 1- Mean values (standard deviation) of fracture resistance and fracture pattern of teeth without and with endodontic access

\begin{tabular}{cccc}
\hline Group & Endodontic access & Fracture Resistance $\mathbf{( K g F )}$ & Fracture pattern (oblique or long axis) \\
\hline CTR & - & $252.41(24.08)^{\mathrm{A}}$ & $50 \%$ oblique \\
NC & No & $95.6(26.66)^{\mathrm{B}}$ & Much variable \\
RU & No & $136.53(11.62)^{\mathrm{C}}$ & $80 \%$ long axis \\
RTB & No & $213.55(11.20)^{\mathrm{D}}$ & $100 \%$ oblique \\
RPB & No & $174.04(43.5)^{\mathrm{CD}}$ & $90 \%$ oblique \\
EC & Yes & $77.59(16.43)^{\mathrm{B}}$ & Much variable \\
EU & Yes & $95.54(13.05)^{\mathrm{B}}$ & $70 \%$ long axis \\
ETB & Yes & $126.51(19.88)^{\mathrm{C}}$ & $90 \%$ oblique \\
EPB & Yes & $100(30.17)^{\mathrm{BC}}$ & $60 \%$ long axis \\
\hline
\end{tabular}

Different superscript letters indicate statistically significant differences $(p<0.05)$

\section{Results}

\section{Teeth without endodontic access/treatment}

Results showed statistically significant difference considering fracture resistance, except for the groups RU/RPB and RTB/RPB, which were similar to each other. Group RTB showed the highest fracture resistance, corresponding to approximately $85 \%$ of the sound tooth resistance. The fracture pattern for the negative control group couldn't be classified because of its variability. For the other groups, the inversion of the fracture pattern could be observed from groups without bevel (RU) for total cavosurface angle beveling (RTB) (Figure 1).

\section{Teeth with endodontic treatment/access}

Results showed statistically significant difference considering fracture resistance. Group ETB showed the highest values for fracture resistance and was statistically similar to group EPB, but still representing about $50 \%$ of the resistance of a sound tooth. Considering fracture pattern, occlusal beveling (group 
EPB) was not capable of changing the fracture pattern when compared with the EU (without beveling), while the beveling of the entire cavosurface angle (group ETB) was able to prevent catastrophic fractures (Table $1)$.

\section{Discussion}

Null hypothesis was rejected because different cavosurface angle treatments influenced fracture resistance and fracture pattern of the groups tested. Cavity preparations in teeth have shown problems related to the fracture resistance of the reminiscent, $1,9,10,12,13,26,27$ and can be responsible for opening of restoration margins, cusp cracks and fractures. Reduction in fracture resistance is even higher considering teeth with endodontic access, and this is related to the removal of reinforcement structures (marginal crests and pulpal chamber roof). ${ }^{2-4,6,11}$ This is in agreement with the present study as the negative control groups (NC and EC) showed statistically lower fracture resistance when compared with the sound teeth group (CTR). All groups with endodontic access showed lower values when compared with the groups without endodontic access. These results confirmed that tooth structure removal can be correlated with lower fracture resistance values, and up to $90 \%$ reduction can be observed in premolars. ${ }^{2,13,27,28}$ This high reduction in resistance can be associated with an "enlargement" of cusps due to premolar teeth anatomy, which may cause a tendency for separation of cusps during masticatory efforts because the restoration acts like a wedge between buccal and lingual cusps, which could result in catastrophic fractures. ${ }^{4,5,13,28-30}$

An operative maneuver for such situations consists of cusp reduction and covering with indirect restorations to protect the reminiscent tooth structure. $4,7,8,30$ Since adhesive restorations can achieve good results in the major part of the cases, reestablishing part of the tooth resistance, such restorations can also be performed with cusp reduction or splinting with resin composites. $2,6,7,13,14,28,30,31$ These results are in agreement with the present study, in which the entire beveling of the cavosurface angle was capable of improving the fracture resistance of the restored teeth simulating the effect of an onlay restoration (Table 1 ).

However, removal of reinforcement structures (i.e. marginal crests), including pulpal chamber's roof removal, has direct impact on the restored tooth resistance ${ }^{1,2,6,8,32}$. Considering endodontically accessed teeth, only groups with the entire cavosurface angle beveling showed fracture resistance increase when compared with the negative control (NC) (Table 1 ). This can be explained by the increase in bonded surface area and better enamel prisms orientation (transversal), resulting in better adhesion and marginal adaption, as well as better force distribution. ${ }^{7,15-17,33-35}$ Such explanations are in accordance with this article results, in which fracture resistance values were increased in the groups with cavosurface angle beveling. The reestablishment of fracture resistance of dental reminiscent is important as well as the fracture pattern that can determine the maintenance of the tooth inside the oral cavity if the restoration fails. Longitudinal fractures usually divide the teeth into two parts, and their extraction is recommended. Oblique fractures are usually restorable.

One can notice an inversion in the fracture pattern from the groups without beveling (groups RU and EU) to the groups with cavosurface angle beveling (groups RTB and ETB). That said, direct composite by itself was unable to reestablish fracture patterns similar to those from sound teeth, but it was capable of restoring the fracture pattern protecting the teeth against catastrophic failure in association with cavosurface angle beveling. The protection provided by the entire cavosurface angle beveling was similar to that reported for onlays, ${ }^{8,13,27}$ despite the lower fracture resistance values when compared with sound teeth.

The results shown in this study considering fracture resistance and fracture pattern reinforces the use of the cavosurface angle beveling to improve the resin composite restoration performance and reliability (Table 1 ). This suggests that increase in bonded area and surface quality allows a better force distribution through the teeth reminiscent.

In the best of authors' knowledge, no studies assessed beveling as a conservative approach for cusp splinting, preventing direct comparison. Nevertheless, this study showed promising results, similar to the above discussed studies assessing fracture resistance with onlays and/or direct restorations with cusp coverage. Future studies should be performed to assess the fracture resistance and pattern under angular loadings, since occlusal forces might dissipate through the restorative material. The use of premolars 
for such tests are ideal due to their anatomy, resulting in enlarged cusps after removal of the roof of the pulp chamber and marginal crests in MOD class II cavity preparations. This fact, associated with axial loading forces without simulation of periodontal ligament (avoiding any "cushion effect"), corresponds to the worst case scenario during tests with axial loading. $4,5,13,14$

Regarding the method, some issues should be addressed. A two-step etch-and-rinse adhesive was used. Although differences in bond strength values are expected considering different bonding approaches (i.e. three- and two-step etch-and-rinse, two- and one-step self-etching and universal), the overall risk ratio of postoperative sensitivity for resin composite restorations placed in cervical lesions and the clinical service are not different when either etch-and-rinse or self-etching adhesives are used. ${ }^{36}$ Moreover, the bonding of two-step etch-and-rinse adhesives to enamel is not affected by the small differences in the application protocol such as in moisture. ${ }^{37}$ The fracture resistance was evaluated after a 7-day storage in distilled water and no thermocycling or further aging was conducted. This was done since this study focused on assessing the influence of enamel beveling on the fracture resistance and pattern in class II restorations with and without endodontic access to provide more comprehension about the beveling per se. Including artificial aging methods in this protocol, addressing the long-term decrease in the bond strength of the resin composite would be interesting, but it would add more variables, and the results could be far more complex to be explained.

In summary, the removal of tooth structure decreases fracture resistance, and restorations are not capable of fully restoring tooth resistance. Nevertheless, beveling of the entire cavosurface angle in class II MOD restorations can improve fracture resistance and fracture pattern of teeth restored with direct composite, and might be recommended in such situations.

\section{Acknowledgement}

The authors deny any conflicts of interest. This study was financed in part by the Coordenação de Aperfeiçoamento de Pessoal de Nível Superior - Brasil (CAPES) - Finance Code 001

\section{References}

1- Teixeira ES, Rizzante FA, Ishikiriama SK, Mondelli J, Furuse AY, Mondelli RF, et al. Fracture strength of the remaining dental structure after different cavity preparation designs. Gen Dent. 2016;64(2):33-6. 2- Mincik J, Urban D. Fracture resistance of endodontically treated maxillary premolars restored by various direct filling materials: an in vitro study. 2016;2016:9138945

3- Eapen AM, Amirtharaj LV, Sanjeev K, Mahalaxmi S. Fracture resistance of endodontically treated teeth restored with 2 different fiber-reinforced composite and 2 conventional composite resin core buildup materials: an in vitro study. J Endod. 2017;43(9):1499-504. 4- Miao Y, Liu T, Lee W, Fei X, Jiang G, Jiang Y. Fracture resistance of palatal cusps defective premolars restored with polyethylene fiber and composite resin. Dent Mater J. 2016;35(3):498-502.

5- Bilgi PS, Shah NC, Patel PP, Vaid DS. Comparison of fracture resistance of endodontically treated teeth restored with nanohybrid silorane, and fiber reinforced composite: an in vitro study. J Conserv Dent. 2016;19(4):364-7.

6- Sangwan B, Rishi R, Seal M, Jain K, Dutt P, Talukdar P. An in vitro evaluation of fracture resistance of endodontically treated teeth with different restorative materials. J Contemp Dent Pract. 2016;17(7):54952.

7- Mondelli RF, Ishikiriama SK, Oliveira Filho O, Mondelli J. Fracture resistance of weakened teeth restored with condensable resin with and without cusp coverage. J Appl Oral Sci. 2009;17(3):161-5.

8- Sharath Chandra SM, Agrawal N, Sujatha I, Sivaji K. Fracture resistance of endodontically treated single rooted premolars restored with Sharonlay: an in vitro study. J Conserv Dent. 2016;19(3):270-3. 9- Mondelli J, Sene F, Ramos RP, Benetti AR. Tooth structure and fracture strength of cavities. Braz Dent J. 2007;18(2):134-8.

10- Zelic K, Vukicevic A, Jovicic G, Aleksandrovic S, Filipovic N, Djuric $M$. Mechanical weakening of devitalized teeth: three-dimensional finite element analysis and prediction of tooth fracture. Int Endod $\mathrm{J}$. 2015;48(9):850-63.

11- Rocca GT, Daher R, Saratti CM, Sedlacek R, Suchy T, Feilzer AJ, et al. Restoration of severely damaged endodontically treated premolars. The influence of the endo-core length on marginal integrity and fatigue resistance of lithium disilicate CAD-CAM ceramic endocrowns. J Dent. 2018;68:41-50.

12- Kemaloglu H, Emin Kaval M, Turkun M, Micoogullari Kurt S. Effect of novel restoration techniques on the fracture resistance of teeth treated endodontically: an in vitro study. Dent Mater J. 2015;34(5):618-22. 13- Alshiddi IF, Aljinbaz A. Fracture resistance of endodontically treated teeth restored with indirect composite inlay and onlay restorations - an in vitro study. Saudi Dent J. 2016;28(1):49-55.

14- Rahman H, Singh S, Chandra A, Chandra R, Tripathi S. Evaluation of fracture resistance of endodontically treated teeth restored with composite resin along with fibre insertion in different positions in vitro. Aust Endod J. 2016;42(2):60-5.

15- Carvalho RM, Santiago SL, Fernandes CA, Suh BI, Pashley DH. Effects of prism orientation on tensile strength of enamel. J Adhes Dent. 2000;2(4):251-7.

16- Wang C, Ou Y, Zhang L, Zhou Z, Li M, Xu J, et al. Effects of regional enamel and prism orientations on bovine enamel bond strength and cohesive strength. Eur J Oral Sci. 2018;126(4):334-42.

17- Schneider PM, Messer LB, Douglas WH. The effect of enamel surface reduction in vitro on the bonding of composite resin to permanent human enamel. J Dent Res. 1981;60(5):895-900.

18- Rizzante FA, Duque JA, Duarte MA, Mondelli RF, Mendonça G, Ishikiriama SK. Polymerization shrinkage, microhardness and depth of cure of bulk fill resin composites. Dent Mater J. 2019;38(3):403-10. 19- Rizzante FA, Mondelli RF, Furuse AY, Borges AF, Mendonça G, Ishikiriama SK. Shrinkage stress and elastic modulus assessment of bulk fill composites. J Appl Oral Sci. 2019;27:e20180132. 
20- Coelho-De-Souza FH, Camargo JC, Beskow T, Balestrin MD, KleinJúnior CA, Demarco FF. A randomized double-blind clinical trial of posterior composite restorations with or without bevel: 1-year followup. J Appl Oral Sci. 2012;20(2):174-9.

21- Brackett WW, Browning WD, Brackett MG, Callan RS, Blalock JS. Effect of restoration size on the clinical performance of posterior "packable" resin composites over 18 months. Oper Dent. 2007;32(3):212-6.

22- Coelho-de-Souza FH, Camacho GB, Demarco FF, Powers JM. Influence of restorative technique, beveling, and aging on composite bonding to sectioned incisal edges. J Adhes Dent. 2008;10(2):113-7. 23- Perdigão J, Anauate-Netto C, Carmo AR, Lewgoy HR, Cordeiro HJ, Dutra-Corrêa $M$, et al. Influence of acid etching and enamel beveling on the 6-month clinical performance of a self-etch dentin adhesive. Compend Contin Educ Dent. 2004;25(1):33-4.

24- Oliveira CA, Dias PF, Santos MP, Maia LC. Split mouth randomized controlled clinical trial of beveled cavity preparations in primary molars: an 18-month follow-up. J Dent. 2008;36(9):754-8.

25- Soliman S, Preidl R, Karl S, Hofmann N, Krastl G, Klaiber B. Influence of cavity margin design and restorative material on marginal quality and seal of extended class II resin composite restorations in vitro. J Adhes Dent. 2016;18(1):7-16.

26- Ozsevik AS, Yildirim C, Aydin U, Culha E, Surmelioglu D. Effect of fibre-reinforced composite on the fracture resistance of endodontically treated teeth. Aust Endod J. 2016;42(2):82-7.

27- Soares PV, Santos-Filho PC, Martins LR, Soares CJ. Influence of restorative technique on the biomechanical behavior of endodontically treated maxillary premolars. Part I: fracture resistance and fracture mode. J Prosthet Dent. 2008;99(1):30-7.

28- Pradeep P, Kumar VS, Bantwal SR, Gulati GS. Fracture strength of endodontically treated premolars: an in-vitro evaluation. J Int Oral Health. 2013;5(6):9-17.
29- Plotino G, Buono L, Grande NM, Lamorgese V, Somma F. Fracture resistance of endodontically treated molars restored with extensive composite resin restorations. J Prosthet Dent. 2008;99(3):225-32. 30- Frankenberger R, Zeilinger I, Krech M, Mörig G, Naumann M, Braun $A$, et al. Stability of endodontically treated teeth with differently invasive restorations: adhesive vs. non-adhesive cusp stabilization. Dent Mater. 2015;31(11):1312-20.

31- Yasa B, Arslan H, Yasa E, Akcay M, Hatirli H. Effect of novel restorative materials and retention slots on fracture resistance of endodontically-treated teeth. Acta Odontol Scand. 2016;74(2):96-102. 32- Ibrahim AM, Richards LC, Berekally TL. Effect of remaining tooth structure on the fracture resistance of endodontically-treated maxillary premolars: an in vitro study. J Prosthet Dent. 2016;115(3):290-5. 33- Lynch CD, O'Sullivan VR, Dockery P, McGillycuddy CT, Rees JS, Sloan AJ. Hunter-Schreger band patterns and their implications for clinical dentistry. J Oral Rehabil. 2011;38(5):359-65.

34- Veneziani M. Posterior indirect adhesive restorations: updated indications and the Morphology Driven Preparation Technique. Int Esthet Dent. 2017;12(2):204-30.

35- Opdam NJ, Roeters JJ, Kuijs R, Burgersdijk RC. Necessity of bevels for box only Class II composite restorations. J Prosthet Dent. 1998;80(3):274-9.

36- Schroeder M, Correa IC, Bauer J, Loguercio AD, Reis A. Influence of adhesive strategy on clinical parameters in cervical restorations: a systematic review and meta-analysis. J Dent. 2017;62:36-53.

37- Furuse AY, Cunha LF, Moresca R, Paganeli G, Mondelli RF, Mondelli J. Enamel wetness effects on bond strength using different adhesive systems. Oper Dent. 2011;36(3):274-80. 